\title{
Límites y «Fronteras» en el Norte Peninsular. Aproximación cartográfica al territorio de Cantabria entre el mundo antiguo y el medieval
}

\author{
Elisa Álvarez LLOPIS \\ Esther Peña Bocos \\ Universidad de Cantabria. UNED-Cantabria
}

In memoriam José Luís Martín

\begin{abstract}
RESUMEN
El objetivo de este breve estudio es reflexionar y aportar un nuevo enfoque sobre los límites del territorio cántabro en la Antigüedad tardía con nuevas pautas, nueva metodologia, nuevas técnicas y con un aprovechamiento exhaustivo de los datos aportados por las fuentes, tanto literarias como cronisticas y eclesiásticas como auxiliares (onomástica, epigrafía o arqueología), que utilizados de forma cartográfica se nos presenta como una forma de delimitar y reconstruir el espacio ocupado por los cántabros en época tardoantigua.
\end{abstract}

\section{PALABRAS CLAVE}

límites, fronteras, territorio cántabro, cántabros, Cantabria tardoantigua, territorios altomedievales.

\section{ABSTRACT}

The object of this brief study is to think about and provide a new approach to the limits of Cantabrian territory in the late ancient times, using new guidelines, a new methodology, new techniques, and making a thorough use of the information provided by the different sources, namely literary, chronicle and ecclesiastic, as well as secondary sources (onomastics, epigraphics and archeological). All of which, used in a cartographical manner, appear as a useful way to delimit and reconstruct the physical space occupied by the cantabrian people in the Late Ancient ages.

\section{KEYWORDS}

Limits, Borders, Caniabrian territory. Cantabrian people, Cantabria, Late Ancient, Early Medieval territories. 
Cuando fuimos invitadas a participar en el volumen de estudios en memoria del prof. José Luis Martín Rodriguez en la Revista Espacio. Tiempo y Forma. Serie III. Historia Medieval, consideramos oportuno honrar la memoria y el oficio de un medievalista como el prof. J. L. Martín y realizar un trabajo que, en principio, iba a llevar por titulo «Fronteras eclesiásticas y políticas en el Norte Peninsular: ¿herencia tardoantigua o creación altomedieval?». Un título que parecia apropiado para unas altomedievalistas que trabajan sobre las áreas más norteñas, que están interesadas en la percepción y organización social del espacio de los primeros tiempos medievales, y que tienen un cierto gusto por cartografiar los fenómenos históricos. Y para ello, y desde la actual Cantabria, pretendíamos realizar un ensayo cartográfico que nos permitiera observar la evolución histórica de un territorio. Máxime en unos tiempos en que prosperan las búsquedas de memorias e identidades haciendo uso y abuso de la Historia, se recrean mitos y héroes, y se utiliza un corónimo, el de Cantabria, que necesariamente no puede significar lo mismo para el siglo XXı que para el siglo I. Sin embargo, "cuestiones de intendencia y convergencia europea" han impedido que este artículo llegue a tiempo para ser editado en dicho volumen-homenaje, lo que no obsta para que las autoras quieran con este trabajo seguir honrando su memoria y oficio de historiador.

Nuestros presupuestos de partida trataban de ahondar en dos líneas de investigación. Por un lado, en uno de los temas no resueltos por la historiografía, como es la desaparición del corónimo Cantabria de un espacio donde supuestamente habitaban los "cántabros irredentos", su deslizamiento hacia otros ámbitos geográficos (riojanos o leoneses), y la sustitución de dicho corónimo por otros de entidad menor, según se recogen en las crónicas y fuentes documentales altomedievales; $y$ a las que tanto nos asimos los historiadores de formación y tradición documental a la espera de que los historiadores de tradición y formación arqueológica nos aporten nuevos datos y documentos que interpretar. Por otro, en comprobar si los fenómenos de organización y articulación política y eclesiástica que conocemos en esos ámbitos territoriales a lo largo de la Edad Media guardan relación con realidades precedentes, son de creación medieval, o son una invención o recreación actual.

Como puede verse, el tema demanda un entendimiento entre antigüistas y medievalistas, y la gran producción científica de unos y otros, y la dispersión de datos no ayuda al encuentro ni al entendimiento. Como tampoco lo hacen las categorias de análisis que unos y otros utilizamos, desde qué coordenadas espaciales trabajamos o bajo qué presupuestos. Unos parten desde los macroespacios de un imperio y sus respectivas provincias. Otros desde los pequeños territorios o espacios comarcales que dieron origen a un condado o un reino. Amén de que llegado este momento debemos de entonar un mea culpa por nuestros ambiciosos planteamientos, reconocer que nos ha desbordado la acumulación de materiales al respecto, y asumir que nuestro homenaje debe ser breve por limitaciones editoriales. De ahí que nos hayamos visto obligadas a limitar nuestra pequeña aportación con una aproximación al territorio de Cantabria entre el mundo antiguo y el medieval, 
aunque con nuevas perspectivas sobre un espacio sobre el que investigadores de talante muy variado han construido buena parte de las interpretaciones que tratan de explicar el arranque de una historia. $Y$ con los mismos documentos que, una y mil veces leídos, y releídos, son los que vuelven a ayudarnos en nuestra empresa de observación e interpretación de lo que sucede en el espacio que se ha vinculado a la Cantabria histórica.

Y en relación con ello hay que señalar que la identidad de Cantabria, como la de cualquiera de los pueblos prerromanos antes de la fase de conquista, es una empresa que entraña dificultades debido a la parquedad de las fuentes y a las diferentes etapas de un largo proceso de dominación, primero romana, y después, visigoda, que ha desvirtuado muchos de sus comportamientos y ha ofrecido en muchos casos una visión lejana y desvirtuada de la realidad al realizarse la redacción de los hechos en fechas posteriores a los actos que se describen. Pues, en un unos casos, se ha realizado bajo la óptica del vencedor, quien ve a los vencidos como seres inferiores; y en otros, los hechos que se transmiten se cuentan a través de relatos intermedios. Otro problema añadido corresponde a la lectura de las fuentes de las que se han hecho diferentes lecturas de un mismo texto, lo que suscita serias dificultades a la hora de su interpretación. Una cuestión que ya fue señalada por Sánchez Albornoz ${ }^{\dagger}$ en 1976, al referirse al pasaje de Mela (II,I) en relación con las diferentes variantes de sus ediciones, lo que se presta a interpretaciones muy variadas.

Por lo que se refiere a la historiografía en relación con el territorio cántabro se puede afirmar que, en la mayor parte de los casos, existe una visión detenida. Pues como se ha puesto de relieve recientemente, lo que se ha escrito sobre la Cantabria tardoantigua «muestra una acusada impronta de las corrientes historiográficas tradicionales y de la erudición eclesiástica de pasadas centurias, habiendo existido una excesiva preocupación por el origen de la cristianización de Cantabria. La continua repetición de los tópicos sobre la invencibilidad y el carácter particularista del pueblo cántabro tampoco resulta ajena a los viejos mitos del vasco-cantabrismo, $y$, aunque ya nadie mantenga la identificación de los cántabros con los euskaldunes, no se duda en extrapolar a la Antigüedad tardía la información de tipo social o etnográfico existente para los cántabros prerromanos»?

En relación con lo anterior parece que algo se está moviendo dentro de esta visión tradicionalista con nuevas interpretaciones de antiguos yacimientos y rectificando teorias hoy desestimadas. Especialmente lo que se refiere a la presencia de Roma en Cantabria, desterrando definitivamente el tópico historiográfico de la resistencia a ultranza de unos cántabros libres y heroicos frente a una potencia coIonial avasalladora, y poniendo en duda teorías y posiciones mantenidas hasta ahora por la historiografía local ${ }^{3}$.

SAnchez Albornoz, C.: Vascos y Navarros en su primera historia. Madrid, 1976, p. 26.

2 Perez Rodriguez Aragón, F.: "La Antigüedad tardía en la Cantabria meridional”, en Iglesias, J. M. y MuNiz, J. M. (Eds): Regio Cantabrorun. Santander, 1999, p. 341.

3 Veáse Fernandez lbañez, C. y Ruiz Cobo, J. (Eds.): La Arqueologia de la Bahía de Santander. Santander, 2003, 3 vols. 
El objetivo de este breve estudio es aportar un nuevo enfoque sobre el territorio cántabro en la Antigüedad Tardía con nuevas pautas, nueva metodología, nuevas técnicas y con un aprovechamiento exhaustivo de los datos aportados por las fuentes, tanto literarias, cronísticas y eclesiásticas como auxiliares (onomástica, epigrafía o arqueología), que utilizados de forma cartográfica se nos presenta como una forma de delimitar y reconstruir el espacio ocupado por los cántabros en época tardoantigua.

Sobre el espacio ocupado por los cántabros existen variedad de teorias aportadas por Assas ${ }^{4}$, Flórez ${ }^{5}$, Schulten ${ }^{6}$, Fernández Guerra ${ }^{7}$, González Echegaray $^{8}$, Sánchez Albornoz ${ }^{9}$, J. J. García González ${ }^{10}$, sin olvidar a Zurita, Gorosabel ${ }^{11}$, Larramendi ${ }^{12}$, Garibay, Henao, o Ambrosio de Morales. En todas ellas aparece como denominador común la frontera oriental del territorio cántabro que unos colocan en el Nervión, otros en el Agüera o en el Asón, lo que sirve para que historiadores como Morales o Garibay se preocupen por la pertenencia de Vizcaya a Cantabria y localicen a Juliobriga en "las marinas de Vizcaya» ${ }^{13}$.

Por lo que respecta a la frontera occidental parece haber unanimidad en el curso del río Sella, que se prolonga hasta Cistierna; mientras que la frontera sur aparece con diferentes alternativas: más arriba o más abajo de Cervera o Herrera de Pisuerga. También parece haber unanimidad en la idea de la localización de los autrigones como frontera oriental de Cantabria, aunque algunos los hacen llegar hasta los Pirineos.

Como podemos observar las teorías son diversas, emitidas algunas hace más de doscientos años y rebatidas o cuestionadas en esa época. Por ello, dedicaremos nuestra atención a las teorias más modernas: la de Sánchez Albornoz (19291976) y la de González Echegaray (1966). Unas teorías que cuentan con más de cuarenta años, y que han sido emitidas con distintas metodologías.

La primera configura el territorio cántabro por exclusión; es decir, delinea primeramente el territorio de las tribus vecinas para concluir en la delimitación de Cantabria, apoyándose en la epigrafía, en los relatos de los geógrafos clásicos, en los datos aportados por la arqueología, y en los de los estudios lingüísticos, teniendo

4 Assas, M.: Crónica de la provincia de Santander. Madrid, 1867.

Florez. E.: La Cantabria. Madrid, 1768.

SCHULTEN, A.: Los cántabros y astures y su guerra con Roma. Madrid, 1943.

Fernandez Guerra, A.: Cantabria. Madrid, 1878.

\& Gonzalez EChegray, J.: Los Cántabros. Santander, 1966.

SANCHEZ AlBORnOz. J.: "Divisiones tribales y administrativas del solar del Pais Vasco y sus vecindades en la época romana» en B. R. A. H, 95 (1929), pp. 315-395. Ibidem: Vascos y navarros en su primera historia. Madrid, 1976 (2. "ed).

10 Garcia Gonzalez, J. J.: "Incorporación de la Cantabria romana al estado visigodo", en Cuadernos Burgaleses de Historia Medieval 2 (1995), pp. 166-230. Garcí Gonzalez, J. J. y FERnANDEZ DE LA MATA, I.: Estudios sobre la transición al feudalismo en Cantabria y la Cuenca del Duero. Cuadernos Burgaleses de Historia Medieval. Anejo I. Burgos, 1999.

"Gorosabel, P.: Noticia de las Cosas Memorables de Guipuzcoa. Libro I. Tolosa, 1899.

1 LARRAMENDI, P.: Discurso histórico sobre la antigua famosa Cantabria. 1736.

it Morales, A.: Chronica General de España, Madrid, 1576, lib. 10, cap. 33 
como elementos auxiliares a la toponimia, y a los textos medievales. La segunda, se apoya en las teorías de Menéndez Pidal ${ }^{14}$ en relación con la pérdida de la "f» inicial, la epigrafía vadiniense, y en la interpretación de textos procedentes de Estrabón, Mela, Plinio, Floro, ... Es decir, que en ambos existe una base común: la proporcionada por los textos clásicos, la epigrafía y la lingüística, aunque Sánchez Albornoz va más allá al complementarla con la toponimia y las aportaciones documentales.

Extraña observar que, tras cuarenta años, ninguna de las dos teorias citadas haya sido motivo de revisión, a pesar de las nuevas traducciones hechas a las obras de Floro, Orosio, Estrabón o Plinio tanto por autores españoles como franceses, ingleses, alemanes o italianos. Cabe pensar que no existe una voluntad de volver sobre temas que algunos califican de "polémicos"; otros, no desean reconocer que nuevas aportaciones, nuevas técnicas y nuevos planteamientos ${ }^{15}$ pueden evidenciar la poca fiabilidad de algunos estudios sobre el tema de la Cantabria tardoantigua que se han llevado a cabo basados en escasos datos; o bien, han obviado el tema.

$Y$ en este sentido, es de notar que algunas teorias como la pervivencia del paganismo, o la escasa romanización entre los cántabros sustentada en la datación del ara descubierta en el Pico Dobra por Alcalde del Río, y fechada en el año $399^{16}$, una nueva lectura corrige su datación y lectura. Realizada por A.U. Stylow, la pareja consular que en ella aparece no es la que siempre se había indicado (Manlio y Eutropio), sino la de Marco Aurelio y Lucio Vero, por lo que siguiendo al autor citado, la fecha más probable para este ara sería la del 161; es decir, que el epigrafe se habría realizado 238 años antes de lo que se pensaba ${ }^{17}$.

De ser esto así, la pervivencia del paganismo y de la organización social de los cántabros hasta fines del siglo IV, no puede seguir manteniéndose. Las consecuencias históricas son importantes tanto para la historia Antigua como para la Medieval. De la lectura del epígrafe citado se derivaba que las relaciones de parentesco y los vínculos territoriales estaban excluidos, puesto que la presencia de un vicanus aunigainum indicaba la existencia de un vicus y por tanto de unos grupos de parentescos que habian evolucionado hacia un grado de territorialización. Pero, como ha señalado González Rodríguez, "existen suficientes testimonios que demuestran que Vicanus es un cognomen, un antropónimo atestiguado como tal en otros hallazgos epigráficos" ${ }^{18}$.

14 Menendez Pidal, R: Origenes del español. Madrid, 1956 (4. ed.), p. 214

15 Aja Sanchez, J. R., Cisneros Cunchillos, M. Diez Castillo, A. y López Noriega, P.: El poblamiento de Montaña en el Sector Central de la Cordillera Cantábrica (España). Berkley, B.A.R, 1999. AJA SanCHEZ, J. R.: Historia y arqueologia de la tardoantigüedad en Cantabria: la "Cohors I Celtiberorum y luliobriga"; un ensayo histórico sobre la "Notitia Dignitatum Occidentis XLII.30". Madrid, 2002

16 Corne(lius) vicanus/ Aunigainu(m)/Cesti f(ilius), aran/ possuit deo Erudino, $X$ ka(lend) is / Augusti Ma(nlio) Eu(tropio) con(n)s(ulibus). Veáse Garcia Bellido, A. y Gonzalez ECHEGARAY, J.: "Tres piezas del Museo Arqueológico Provincial de Santander", AEArq (1949). XXII, n. 76, pp. 241-247.

17 Gonzalez Rodriguez, M. C.: “Estructuras sociales indígenas entre los pueblos del Norte», en Rodriguez Neila, J. F. Navarro Santana, F. J. (Eds.): Los pueblos prerromanos del Norte de Hispania. Una transición cultural como debate histórico. Pamplona, 1998, pp. 327

18 loidem, p. 327. 
Por su parte, Besga Marroquín lleva más allá las consecuencias en relación con la teoría de A. Barbero y M. Vigil sobre la situación de cántabros y astures que se plantea en su obra Sobre los origenes sociales de la Reconquista, ya que piensa que en las fuentes "no existe ninguna noticia de insumisión, rebelión, independencia o guerra de los pueblos del Norte peninsular en la época del Bajo Imperio. Lo único que existe, en realidad, son interpretaciones (brevemente argumentadas) de algunos datos, que serían indicios (que no pruebas) de esa independencia». Una teoría que está basada también en la inscripción del Pico Dobra ${ }^{19}$.

Pero volvamos a los límites de Cantabria. Sobre ellos ambas teorias coinciden, al igual que las de otros autores como hemos apuntado, en señalar el curso del río Sella como la frontera Oeste de los cántabros. Un límite bien definido por los textos y por la epigrafía vadiniense que se extiende desde la riberas del Sella hacia el SO. hasta el lugar de Cistierna para dirigirse hacia Velilla de Río Carrión, identificada con las Fuentes Tamarici señaladas por Plinio, como perteneciente a los cántabros.

La divergencia entre ambas teorías comienza al delimitar la zona SO. Para González Echegaray la línea de frontera desde las fuentes del Sella en el valle de Sajambre, se dirigiría hacia Cofiñal, para replegarse al SE. hasta Cistierna. Desde aqui la divisoria estaría entre Alar del Rey y Mave, quizás después de pasar Nogales de Pisuerga, desde este lugar el inicio de la zona montañosa señalaría el paso hacia el interior de Cantabria por la vaguada del Pisuerga. Queda por tanto más al Este el castro de Peña Amaya, que estaría según esta interpretación en territorio turmogo. Una línea que González Echegaray califica de difusa se dirigiria hacia el nordeste, a través de Valdelucio y La Lora hasta el lugar de Paradores de Bricia, pasaria cerca de Villarcayo, dirigiéndose hacia los Montes de Ordunte. La linea se cerraria atravesando estos montes, para descender con el curso del Agüera, hasta la ría de Oriñón, que delimitaría la frontera oriental.

Sánchez Albornoz por su parte, desde Cistierna hace pasar la frontera, tras trazar una ligera curva hacia el Sur, hacia Guardo. Desde allí seguiría una línea ascendente hasta el sur de Cervera de Pisuerga, más o menos coincidente con el territorio de La Pernía; una inflexión en la línea de frontera la llevaria hasta Treviño, para dirigirse después hacia Villadiego y Páramo de Masa hasta Terminón, como punto más oriental de Cantabria. Desde este punto, la línea fronteriza coincide con el territorio autrigón en dirección norte con las divisorias de los ríos Rudrón, del Nela y del Ebro, divisorias que coinciden con las merindades de Bureba y Castilla Vieja. Esta línea ascendería por el puerto de la Magdalena por la divisoria del valle de Luena con el del Pas, valle este último que quedaría fuera del territorio cántabro, para a lo largo del curso alto del río Pas enlazar con el Asón, río que servirá de frontera entre los territorios cántabro y autrigón, dejando dentro de éste último los valles de Soba y Ruesga y la peninsula de Santoña.

19 Besga Marroouin, A.: Origenes hispanogodos del reino de Asturias. Oviedo, 2000, pp. 80-81. 


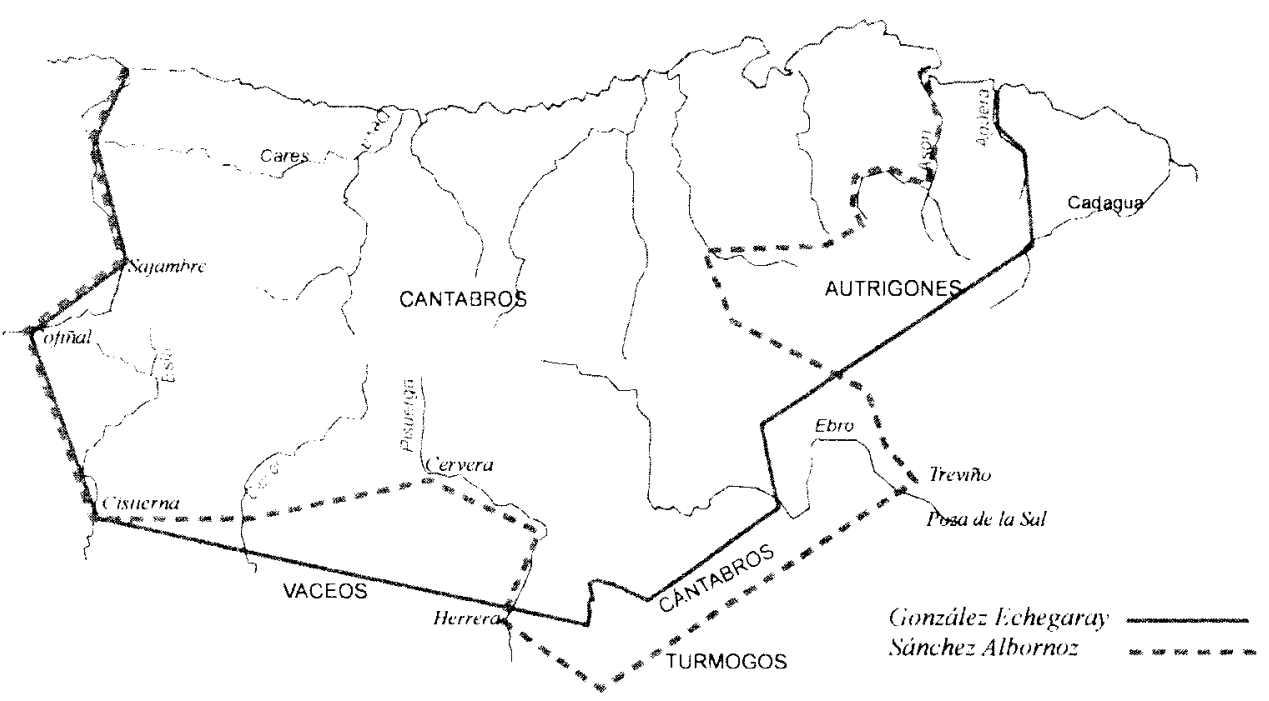

Mapa 1. Límites y fronteras del territorio cántabro.

En el Mapa 1 representamos cartográficamente las dos teorias que en relación con los límites y "fronteras" hemos venido comentando hasta aquí.

Por lo que respecta a ambos trazados del territorio cántabro creemos que posiblemente la teoría de Sánchez Albornoz tiene más visos de verosimilitud que la de González Echegaray, aunque en algunos tramos ambos sean coincidentes como ya hemos señalado en el trazado occidental, más seguro por las aportaciones epigráficas vadinienses y las fuentes clásicas.

En el Mapa 2 hemos plasmado el territorio que según la teoría de Sánchez Albornoz correspondería a los cántabros, cuyo punto situado más al SE correspondería a Treviño (Burgos), punto de confluencia de vaceos, turmogos y cántabros, al igual que en el Treviño (Burgos) del SE. concurren cántabros, várdulos y caristios.

Como se puede observar la imágen que se nos presenta recuerda en gran parte a la actual, salvo algunas diferencias. Lo primero que nos llama la atención en el trazado occidental son los territorios primoriense y lebanense. El primero de ellos, parece ser el escenario en que se desarrollan las primeras manifestaciones que darán lugar al incipiente reino astur. Un territorio localizado en la franja de la marina oriental de Asturias tradicionalmente ocupado por los cántabros orgenomescos, comprendido entre los ríos Deva y Ribadesella y localizado al norte del territorio lebaniense o vadiniense. En este espacio se situará el escenario de los acontecimientos de Covadonga y el primer centro político del naciente reino asturiano: Cangas de Onís. Tras los acontecimientos políticos del 711 el territorio primoriense pasa a formar parte del espacio asturiano, habiéndose producido así un desplazamiento onomástico y étnico de la zona oriental astur hacia el occidente cántabro 


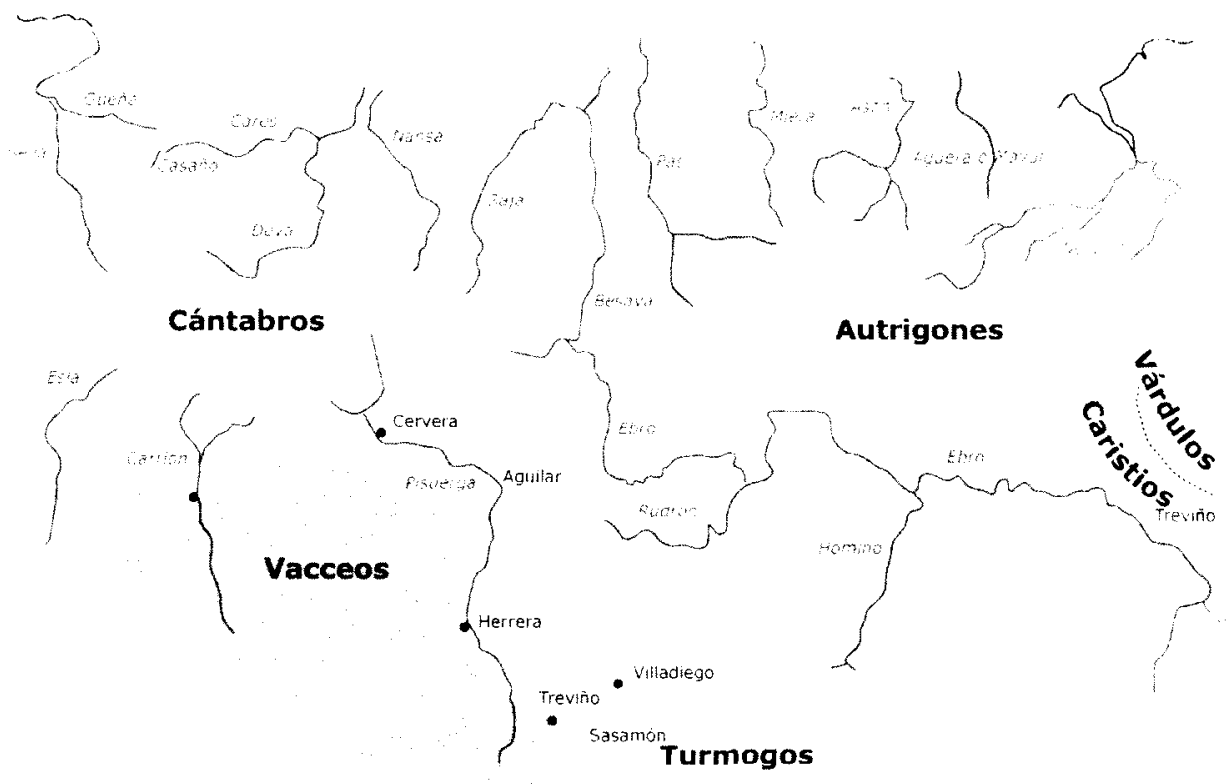

Mapa 2. El territorio cántabro.

y la pérdida del corónimo Cantabria. Pero creemos que, este desplazamiento, no se realiza sobre todo el territorio primoriense, ya que los valles de Peñamellera, Rivadedeva, Cueto de Arriba y Cueto de Abajo permanecerán dentro de la jurisdicción de las Asturias de Santillana hasta el Real Decreto de 1833. Y en virtud del cual se agregaban los citados valles con sus términos al partido de Llanes, que eran de la provincia de Santander ${ }^{20}$. Es decir, que el espacio comprendido entre Llanes y el Deva siguió dentro de la jurisdicción cántabra, como se puede observar en el Atlas de El Escorial ${ }^{21}$, de 1570. Este mismo límite se plasma también en los de Jan Blaeu (1596-1673), Nicolás Sanson d'Abbeville (1600-67), Nikolaes Visscher (1639-1709), Frederik de Wit (1610-1698) o en el de Jaillot (1632-1712), entre otros.

Por su parte, La Liébana ha merecido un estudio desarrollado a partir de las fuentes y crónicas altomedievales, donde se ha planteado la extensión del terrritorio libanense citado en las fuentes ${ }^{22}$. Como quiera que los primeros datos sobre

20 CASAdO Soto, J. L.: «La provincia de Cantabria. Notas sobre su constitución y ordenanzas (17271833)", en Altamira I (1978), pp. 123-195. La documentación de estos valles se encuentra en el A.H.P. de Cantabria.

21 Atribuido a Pedro de Esquivel, se encuentra en la Biblioteca del Monasterio de San Lorenzo de El Escorial, y contiene la primera mención cartográfica de las cuatro villas.

22 Álvarez LlopIS, E.: La Liébana medieval, siglos IX a XIII: instalación humana y actividades económicas. Tesis doctoral inédita. Universidad de Cantabria. 1993, pp. 67-76. 


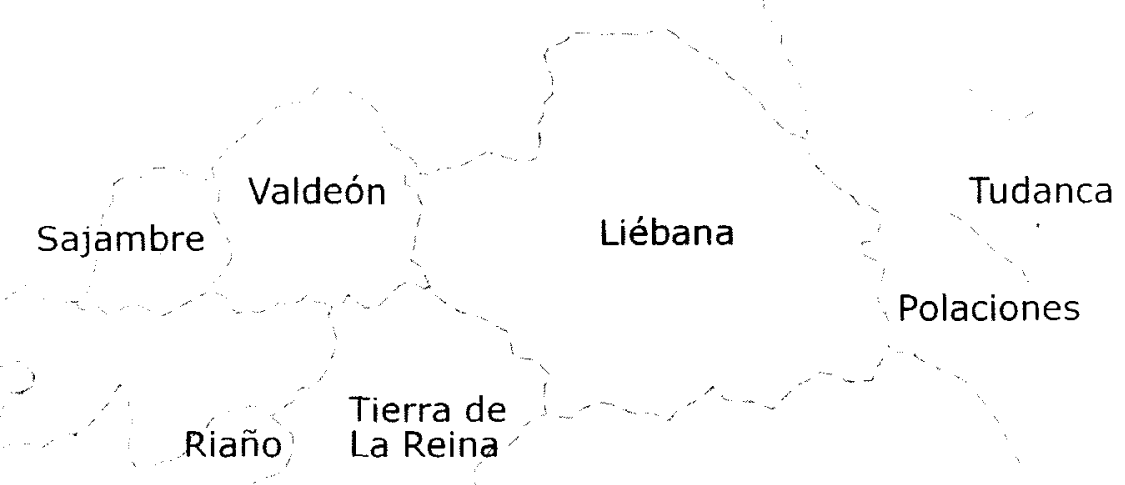

Pernía

Mapa 3. El territorio lebaniense.

este territorio corresponden a la última década del siglo VIII, es decir, cuando ya se había configurado el reino asturiano, este espacio reproduce una imagen posterior que casi coincide, salvo la zona primoriense que parece haberse incorporado a la zona asturiana.

Además de los valles de la actual Liébana, dicho territorio comprendía Feñarrubia y Peñamellera baja; es decir, la franja comprendida entre el río Cares y el actual límite norte de la comarca lebaniega. Al Oeste, los valles de Valdeón y Tierra de La Reina, limitados por la sierra de Riaño. El sur queda delimitado por el espacio comprendido entre los valle altos del Pisuerga y del Carrión, la sierra del Brezo y La Pernía. Es decir, que el territorio lebaniense ${ }^{23}$ conservará los límites acuñados históricamente desde época prerromana, coincidiendo en su mayor parte con los límites señalados para los cántabros vadinienses.

El territorio lebaniense se configurará como la frontera más nororiental del reino de León tanto frente a Castilla, desde época de Fernán González (923), como hasta Sancho III y Alfonso VIII, que pasa a ser castellana. Y será frontera del reino de Navarra desde la muerte del conde Garcia Sánchez (1029) a la de Bermudo III de León. Eclesiásticamente, la Liébana estará adscrita a la diócesis de León hasta 1956. Según Mañaricua, la división geográfica eclesiástica coincide con la muy

23 Ibidem. Un resumen sobre la misma en ÁLVAPEZZ LLOPIS, E.: "Introducción a la Liébana Medieval", en Estrada Sanchez, M. y Sanchez Gómez, M. A. (Eds.): La Liébana. Una aproximación histórica. Torrelavega, 1996, pp. 77-92. 
anterior geografía tribal y lingüistica en relación con el Pais Vasco ${ }^{24}$. Creemos que esta tesis podría ser extensiva al territorio lebaniense, pues geográficamente coincide con los vadinienses y lingüísticamente con el límite donde se pierde la «f» inicial $^{25}$.

La división del territorio en distritos de límites variables en el reino astur-leonés, bajo el mando de un comes, preservó la extensión del territorio hasta la configuración de la merindad, que sustituye al condado a principios del siglo xIII y articula administrativamente el territorio en dos espacios diferenciados: la merindad de Liébana-Pernía, que comprendía los valles de Liébana, Valdeón, Pernía y Polaciones; y la de Valdeburón, en la que se integraban Sajambre, Tierra de La Reina y Riaño. Las sucesivas divisiones administrativas que se realizan en los siglos XVI, XVIII y XIX (se crea la provincia de Liébana), y en la división de Javier de Burgos (1833), que perdura hasta la configuración de las actuales comunidades autónomas, terminan por desdibujar el territorio lebaniense.

Con respecto a la frontera oriental el proceso que hemos utilizado ha sido inverso al que hemos llevado anteriormente, hemos partido de la configuración realizada en 1799, fecha en la que las provincias castellanas se amplian a 37, para retroceder hasta la primera separación de Asturias de León y Castilla la Vieja, dividiéndose la Península en 24 provincias, hasta llegar a fines del XVI, cuando Castilla se divide en 18 provincias, y el territorio leonés se componía de tres partidos: León, Ponferrada y Principado de Asturias, comprendiendo este último Asturias de Santillana y Liébana. Es decir, que hasta fines del siglo XVI creemos que puede pervivir la división en las antiguas merindades castellanas ${ }^{26}$.

A partir de las merindades de Asturias de Santillana, Trasmiera y Castilla Vieja hemos establecido su trazado sobre el mapa de la actual comunidad autónoma así como los dos trazados que estamos analizando y su resultado lo hemos plasmado en el Mapa 4.

Dicho mapa permite observar dos aspectos de gran interés: por un lado, que la merindad de Castilla Vieja, dentro de la actual Cantabria, reproduce en mayor o menor medida el territorio ocupado por los autrigones y sigue el trazado dado por Sánchez Albornoz para la zona oriental; por otro, que el río Asón y los valles de Soba y Ruesga que delimitan la merindad de Trasmiera ${ }^{27}$, así como el valle del

24 Mañaricua, A.: Obispados en Álava, Guipúzcoa y Vizcaya a fines del siglo xi. Vitoria, Eset, 1963. También A. Campeón ha advertido de la coincidencia entre la antigua geografía tribal y la dialectal moderna en "La lengua baska» en CARRERAS CANDI, Geografia general del País Vasco-Navarro. Barcelona, [1910?], 5 vols.; vol. 1, p.197.

${ }^{25}$ Menendez Pidal, R.: Origenes del español. Madrid, 1956 (4. ${ }^{a}$ ed.), p.214.

${ }^{26}$ En la documentación de la época se pueden encontrar frecuentemente alusiones al envío de propios de una merindad a otra o el reconocimiento de unos límites jurisdiccionales.

27 Veáse el mapa de la merindad de Trasmiera en Sojo y LOMBA, F. de: llustraciones a ia historia de la M.N y S.L. Merindad de Trasmiera. Madrid, 1931, 2 vols. Y en relación con esos ámbitos el reciente libro de Baro Pazos, J., Estrada Sanchez, M. y Serna Vallejo, M.: De la Junta de Sámano al Ayuntamiento constitucional (1347-1872). Santander, 2004. 


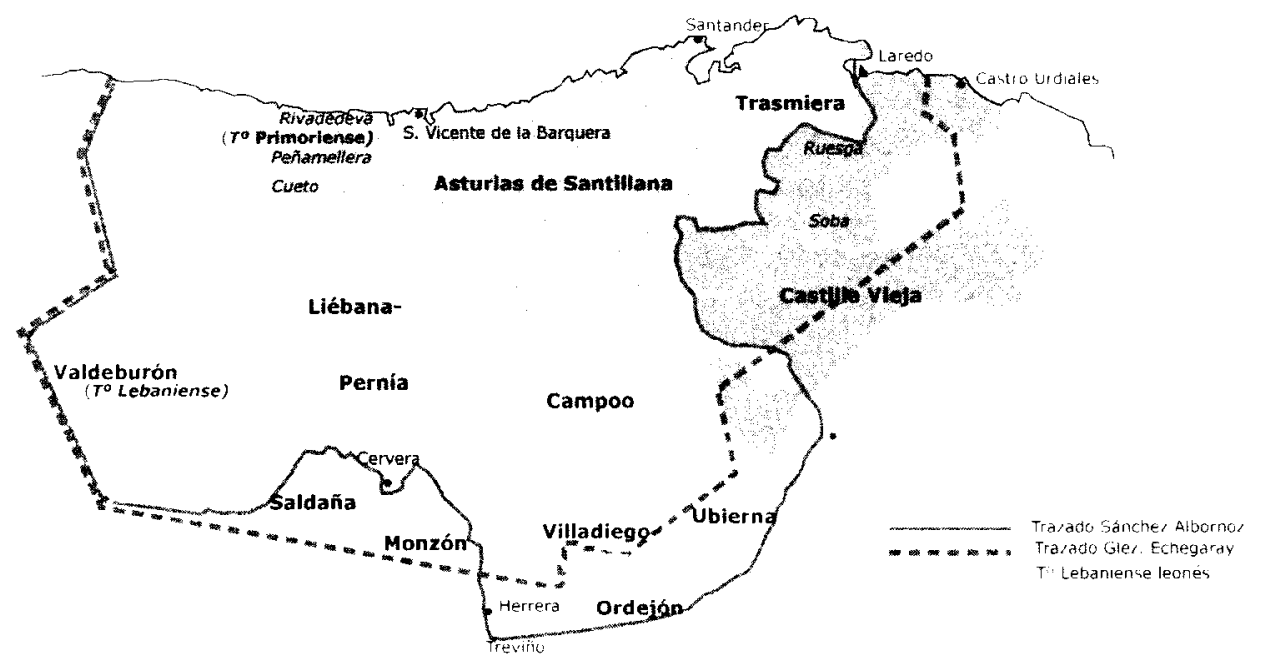

Mapa 4. De la Cantabria tardoantigua a las merindades castellanas.

Pas, integrado dentro de la merindad de Castilla Vieja, delimitan el trazado de la frontera oriental apuntado por Sánchez Albornoz.

$Y$ esta imagen cartográfica con sus variantes parece ser la que se asume para la Cantabria de época visigoda por los especialistas del período, y a la que se califica de probable provincia de Cantabria, circunscripción, o ducado de Cantabria ${ }^{28}$, que a decir de esos mismos especialistas, junto con el de Asturias, "debieron ser creados en algún momento comprendido entre el 653 y el 683". Un periodo del que, a pesar de los distintos y valiosos intentos de aproximación realizados en los últimos veinte años, aún sabemos poco o no sabemos enlazar con la idea de organización social del espacio que tenemos los altomedievalistas del Tercio Norte Peninsular. Quizá porque estamos influenciados por la imagen que nos ofrecen las Crónicas Asturianas cuando, haciendo referencia a las campañas llevadas a cabo por Alfonso I un siglo después, el espacio, al decir de las crónicas, se articula territorialmente en unidades de organización territorial conocidas ya para el mundo romano: civitates, seu castris cunm suis villis et viculis suis. $Y$ son esas mismas crónicas las que nos ponen en contacto con unas realidades territoriales en las que desaparece el corónimo de Cantabria como nombre englobador de un pueblo para ser sustituido por «Asturias, Primorias, Liébana, Trasmiera, Sopuerta, Carranza, Las Vardulias, que ahora llaman Castilla, y la parte marítima de Galicia;..." como realidades territoriales diferenciadas. Unos territorios

28 Revuelta Carbajo, R.: La ordenación del territorio en Hispania durante la antigüedad Tardia. Madrid, 1997. MONTENegro, J. y CAStILlo, A. del: "Don Pelayo y los orígenes de la reconquista" en Hispania, LIl (1992), pp. 5-32; Idem: "En torno a la conflictiva fecha de la batalla de Covadonga", en Anales de la Universidad de Alicante. Historia Medieval, 8 (1992), pp. 7-18; Garcia Moreno, L. A.: «Estudios de la organización administrativa del reino visigodo de Toledo" en A.H.D.E. XLIV (1974), pp. 5-51. esp. 12-21. 
que parece fueron reorganizados por el propio Alfonso I, quien según esas mismas crónicas afirman, en su versión Rotense, era «hijo de Pedro Duque de los Cántabros, de regio linaje»; $y$, en su versión "A Sebastián», "era hijo del duque Pedro, descendiente del linaje de los reyes Leovigildo y Recaredo, ( $y$ ) en tiempo de Egica y de Vitiza fue jefe del ejército " ${ }^{29}$.

Una imagen, la del espacio ocupado por los cántabros, que todavía para el siglo $V$ sigue vigente en Hidacio (49) cuando describe el reparto por sorteo de las provincias romanas entre los diferentes pueblos bárbaros, un reparto que parece utilizar las antiguas demarcaciones romanas y recordar antiguas entidades étnicas con la mención de un ataque de los hérulos por mar a la tierra de los cántabros (Hydat. 171). Asimismo, el historiador Jordanes (Get. XLIV) conserva la memoria de la Autrigonia prerromana cuando menciona los límites orientales de los suevos. La predicación de San Millán a los jefes cántabros en Amaya, en el último tercio del siglo vi, o el ataque de Leovigildo a Cantabria, son datos que quizás permitan aceptar la pervivencia de viejas estructuras, al menos hasta mediados del siglo VII, como prueba la creación de dos circunscripciones territoriales o ducados: Asturias y Cantabria. Aunque sus límites nos son desconocidos, la antigua capital de los cántabros, Amaya, se constituye en capital de la nueva demarcación hasta el 714 , fecha en que fue destruida por los musulmanes. Por su parte, la administración visigoda intentó conservar y recuperar, o adecuar, la estructura administrativa romana. $Y$ esta prolongación es evidente también a través de las sedes episcopales que siguen el esquema organizativo bajoimperial, superponiéndose la administración religiosa a la civil ${ }^{30}$, y coincidiendo dichas sedes con la residencia del comes o iudex responsable de la administración civil del territorio ${ }^{31}$.

No cabe duda de que las Crónicas Asturianas nos ofrecen la imagen de una organización espacial y unas realidades territoriales que no nos son desconocidas a los medievalistas, puesto que, con ligeras variantes o reestructuraciones, éstas perviven a lo largo de la Edad Media. Lo que ya no tenemos tan claro es si esta percepción territorial diferenciada es anterior al 711 , una nueva organización del siglo VIII, o una realidad territorial propia del momento en que se escriben esas Crónicas (siglo $\mid X$ ). Y ello, a pesar de que para algunos especialistas de la Antigüedad parece claro que la romanización respetó, cuando no aprovechó, la organización anterior a un nivel de estructura inferior a las provincias, y lo mismo hicieron los visigodos. Mientras que otros lo dudan. Lo que está claro es que los nombres no surgen de la nada, otra cosa es la realidad territorial que tratan de aglutinar según tiempos.

Sea como fuere, y desde cuándo, no lo sabemos. Pero no nos cabe duda alguna de que la institución que más memoria ha conservado es la Iglesia, y tam-

29 Gil fernandez, J., Moralejo, L. y Ruiz de la Peña, J. I. (Eds.): Crónicas Asturianas. Gviedo, 1985.

30 Albertini, E.: Les divisions administratives de l'Espagne romaine. París, 1923. pp. 119 y ss.

"11 Garcia Moreno, L. A.: “Estudios de la organización administrativa...”, pp. 8 y sS.; P. D. KING: Derecho y sociedad en el reino visigodo. Madrid, 1981, pp. 99 y ss. 
poco cabe duda del papel que dicha institución jugó en la definición y articulación del territorio peninsular. Basándose en la relación de sedes episcopales citadas en la falsa Hitación de Wamba la Iglesia planificó su reconstrucción territorial a imagen de la antigua iglesia visigótica sobre los territorios reconquistados o por reconquistar, aunque ésta estuviera sometida a las conveniencias políticas o coyunturales, como han sugerido Vázquez de Parga o Mansilla ${ }^{32}$. Ello supuso la convivencia de dos estructuras paralelas pero diferentes, organización política y organización eclesiástica. Sus diferencias estriban en las motivaciones alegadas para su imposición. La primera se basaba en una imposición basada en las armas. La segunda busca imponerse, al menos teóricamente, por via legal, como restauración de antiguas sedes episcopales, teniendo todo territorio eclesiástico una base jurídica, sancionada por la autoridad de Roma. La existencia de dos organizaciones paralelas dio origen a numerosos conflictos territoriales, por lo que era necesario explicitar documentalmente la extensión de las jurisdicciones respectivas dando origen a una serie de textos de carácter geográfico en los que quedan reflejados la realidad geopolítica del momento ${ }^{33}$. Por todo ello, pensamos que la organización eclesiástica junto con la organización político-territorial pueden ser una pista de unión entre los antiguos límites cántabros ${ }^{34}$ y la configuración de los territorios citados en las Crónicas y documentos medievales.

32 VAzQuez de PARga, L.: La division de Wamba. Madrid, 1943; MAnsilla Reoyo, D.: Iglesia castellano-leonesa y Curia romana en los tiempos del rey San Fernando: estudio documental sacado de los registros vaticanos. Madrid, C.S.I.C., 1945, pp. 93-98.

${ }^{33}$ Gracias al cardenal Gil Torres, podemos conocer la primitiva extensión y articulación de las diócesis de Burgos, Calahorra, Ávila y Segovia a mediados del siglo xliı. El correspondiente a la diócesis de Burgos fue publicado por el P. FLoREZ, España Sagrada 26, contiene el estado antiguo de las iglesias de Auca, de Valpuesta, y de Burgos. Burgos, 1983 (Reedic.), pp. 482-489.

${ }_{34}$ Todos los mapas han sido elaborados a partir de la escala 1:200.000. 